University of Windsor

Scholarship at UWindsor

2006

\title{
An exploratory study of cross-cultural adaptation of adolescent Taiwanese unaccompanied sojourners in Canada
}

\author{
B.C.H Kuo \\ University of Windsor \\ Gargi Roysircar
}

Follow this and additional works at: https://scholar.uwindsor.ca/psychologypub

Part of the Psychology Commons

\section{Recommended Citation}

Kuo, B.C.H and Roysircar, Gargi. (2006). An exploratory study of cross-cultural adaptation of adolescent Taiwanese unaccompanied sojourners in Canada. International Journal of Intercultural Relations, 30 (2), 159-183.

https://scholar.uwindsor.ca/psychologypub/20

This Article is brought to you for free and open access by the Department of Psychology at Scholarship at UWindsor. It has been accepted for inclusion in Psychology Publications by an authorized administrator of Scholarship at UWindsor. For more information, please contact scholarship@uwindsor.ca. 


\title{
An exploratory study of cross-cultural adaptation of adolescent Taiwanese unaccompanied sojourners in Canada
}

\author{
Ben C.H. Kuo,*, Gargi Roysircar ${ }^{\mathrm{b}}$ \\ ${ }^{a}$ Department of Psychology, University of Windsor, 401 Sunset Ave., Chrysler Hall South, Windsor, Ont., \\ Canada N9B $3 P 4$ \\ ${ }^{\mathrm{b}}$ Department of Clinical Psychology, Antioch New England Graduate School, 40 Avon Street, Keene, \\ NH 03431-3516, USA
}

Received 16 November 2004; received in revised form 25 July 2005; accepted 25 July 2005

\begin{abstract}
Increasing accessibility and the demand for international education globally has engendered a new wave of international students of diverse demographic backgrounds and developmental characteristics. The appeal of studying in western, English-speaking countries is strong even among very young adolescents from East Asia. However, existing literature on international students has largely overlooked this younger sojourner population. Thus, little is currently known about the effects of developmental and cultural factors on the cross-cultural adaptation of these teenage international students. In this exploratory study, the psychological well-being and adaptation of adolescent Taiwanese unaccompanied sojourners $(N=201)$ attending secondary schools in a large Canadian city were examined. The study first investigated the participants' perceived preparedness for studying in Canada. A significant number of these students reported feeling ill-prepared and poorly oriented upon their arrival in Canada, as well as suffering from a lack of information about their host country and their purpose for sojourning. The study then tested a path model of adaptation based on six variables emerged from a quantitative survey and conceptualized within the acculturation and ethnic identity frameworks. The four predictors were perceived prejudice, education-related
\end{abstract}

\footnotetext{
${ }^{*}$ Corresponding author. Tel.: + 1519253 3000x2238; fax: + 15199737021.

E-mail addresses: benkuo@uwindsor.ca (B.C.H. Kuo), g_roysircar-sodowsky@antiochne.edu (G. Roysircar).
} 
acculturation, interpersonal competence, and age of arrival; the two criterion variables were acculturative stress and ethnic identity. In the best-fitting model, education-related acculturation reduced acculturative stress while perceived prejudice contributed to such stress. However, the predictor variables' relationships with the criterion variables were mediated by interpersonal competence. Implications for future research, counseling, and cross-cultural training with teenage sojourners are discussed.

(C) 2005 Elsevier Ltd. All rights reserved.

Keywords: Acculturation; Acculturative stress; Ethnic identity; Unaccompanied sojourners; International students

\section{Introduction}

The effects of globalization can be observed in the domain of education. In Canada, the ever-increasing international student population and ethnic diversity in classrooms and campuses across Canada is a clear example of this trend (Canadian Bureau for International Education (CBIE), 2002). This is partly the result of a push to internationalize Canadian education as well as an increase in demand for international education worldwide (CBIE; Knight, 2000). During 1999-2000, the number of international students in Canada reached an all-time-high of 106,068, representing students from 207 countries and an increase of $20.9 \%$ from 1993 to 1994 period (CBIE). In view of this growing foreign student population, some have noted the adjustment issues of this group, particularly its vulnerability to acculturation strains and isolation (Kuo \& Roysircar, 2004; Leung, 2001a; Zheng \& Berry, 1991). Others have pointed to a critical need for specific interventions with international students (Leong \& Chou, 2002; Pedersen, 1991; Roysircar, 2004). Consequently, the uniqueness of young sojourners has direct implications for both research and program provisions for these international students.

The current study is an exploratory examination of the cross-cultural adaptation of a distinct group of teenaged international students, Taiwanese unaccompanied sojourners, living in Toronto, Canada. Based on a quantitative survey questionnaire developed specifically for this population, the study assesses Taiwanese unaccompanied sojourners' perceived readiness and preparedness for overseas study. In addition, the study seeks to test key adaptation variables emerged from the questionnaire and the variables' relationships in path models conceptualized within acculturation and ethnic identity literature (Berry, 1997; Kim \& Abreu, 2001; Roysircar-Sodowsky \& Maestas, 2000). Finally, implications and recommendations for counseling, educational interventions, and cross-cultural training for young international students are put forth.

\subsection{Background of Taiwanese unaccompanied sojourners}

Historically, empirical research on international students has been dominated by studies of post-secondary students in North America (see Leong \& Chou, 2002 for a 
recent literature review). The experience of younger, adolescent international students in high school and middle school has been largely overlooked by this body of literature (Pedersen, 1991; Sieu, 1998). In the past decade and a half, a unique group of international students from Asian countries starting education in North American high school systems has emerged (Hong, 1998; Lin, 1992, 1998).

These students are characterized by their young age, as many of them are legal minors who are not accompanied by their parents. These children and adolescents have been referred to as "unaccompanied minors", "parachute kids", "little overseas students", and "visa students" (Hwang \& Watanabe, 1990; Lin, 1992). Here, we use the term "unaccompanied sojourners" to refer to this group. Unaccompanied sojourners' distinctive characteristics pose interesting empirical questions and practical implications regarding their development, well-being, and cross-cultural adjustment (Leung, 2001a; Ying, 2001). However, they remain obscured from public and scholarly examinations.

In 1999-2000, there were 33,576 of these young sojourners in Canada, representing $32 \%$ of the total Canadian international student populations (CBIE, 2002). As high as $40 \%(12,937)$ of these students originated from Asia. In the US, some early estimates suggested that 30,000-40,000 unaccompanied sojourners from Taiwan between ages 8 and 18 lived in the US, with about 10,000 estimated to be in the West coast alone (Forden, 1990; Hwang \& Watanabe, 1990; Kuo, 1991). The large-scale departure of young students from East Asian countries began in the 1980s in response to a number of motivating factors: (1) social, political, and economic instability in countries in Asia; (2) their highly competitive academic systems; and (3) the parents' intention to immigrate to the foreign country where their children are studying (Chen, 1997; Cheng, 1994; Lin, 1998). Ying (2001) noted that the severing of diplomatic ties between Taiwan and the US in 1979, and the return of Hong Kong to China in 1997 generated considerable anxiety among many Chinese parents and contributed to their desire to send adolescent children abroad.

\subsection{Literature on unaccompanied sojourners}

Taiwan represents a major sender of adolescent unaccompanied sojourners to North America. In Canada, during 1999-2000, elementary/secondary international students from Taiwan ranked second (following South Korea) among Asian countries with a total of 2193 (CBIE, 2002). Despite East Asian unaccompanied minors' growing presence in North America, research on them has been sparse and lacking in theoretical basis (Sieu, 1998), partly due to insufficient official records (Kim, 1998; Lin, 1998). Relevant discussions have largely been journalistic writings (e.g., Chen, 1991; Gordon, 1993; Hamilton, 1993; Watanabe, 1989) and anecdotal reports (Lin, 1992, 1998). There are only a handful of empirical studies on Chinese unaccompanied students, and these appear in the form of dissertations and theses (e.g., Cheng, 1994; Chung, 1994).

More recently, Kuo and Roysircar (2004) studied three cohorts of Chinese Canadian adolescents in Toronto. The results indicated that the Chinese international students had the lowest acculturation level and the highest acculturative stress 
in comparison to their counterparts who were born and raised in Canada. These sojourners were more similar to their immigrant counterparts, who were more recent arrivals in Canada. Similarly, Ying (2001) studied three Chinese subgroups in the US, accompanied minors, unaccompanied adults, and unaccompanied sojourners. She found unaccompanied sojourners to be more likely to withdraw themselves to aspects of the Chinese culture, and to sustain a greater bond with their past (traditional values) as compared to the other two groups. These rare studies have provided limited but important clues to the ethnic identity of unaccompanied sojourners.

In regards to their well-being, the cumulative report suggests that unaccompanied sojourners experience: (1) significant cross-cultural adjustment difficulties (Hwang \& Watanabe, 1990; Kuo, 1991; Lin, 1992); (2) significant education-related concerns (Chow, 1990; Lee, 1994); (3) substantial psychological problems (Cheng, 1994; Chung, 1994; Lin, 1992). However, a more comprehensive examination of unaccompanied sojourners as well as the relationships among factors related to their adaptation remains to be desired.

\subsection{Literature on cross-cultural adaptation variables pertinent to the present study}

Accumulative literature on cross-cultural adaptation has pointed to key cultural variables that are critical to adjustment process and outcome (Berry, 1997). Among these variables, acculturation and ethnic identity are among the most widely investigated adaptation constructs (Berry, 2005; Roysircar-Sodowsky \& Maestas, 2000). Yet to date, no known studies have applied these cultural conceptualizations systematically to comprehend the adaptation experiences of teenage sojourners from Asia. Therefore, grounded in the cross-cultural adaptation literature (Ward, 2001), this present study develops a survey questionnaire and tests conceptual models of acculturation and ethnic identity for Taiwanese unaccompanied sojourners. The following sections are brief reviews of the theoretical and empirical works related to the adjustment of Asian immigrant youth and young sojourners.

The theory of acculturation explains the changes that occur in cultural transition (Kim \& Abreu, 2001). It predicts changes in language, cognitive style, personality, identity, attitude, and produces acculturative stress for the individual undergoing cultural changes (Berry, 1997). In general, Asian international students in North America have been found to be less acculturated than their North American-born and immigrant counterparts (Kuo \& Roysircar, 2004; Zheng \& Berry, 1991). It has also been noted that young international students' competencies in academic (Leung, 2001b) and linguistic domains (Ying, 2001) in the host society are particularly critical to their adaptation and central to their overall acculturation experiences. For instance, Leung (2001b) found academic satisfaction to be positively correlated to social self-efficacy and negatively correlated to loneliness among Chinese immigrants and international university students in Australia. In Canada, the academic success of Chinese Canadian adolescents was found to negatively correlate to their level of stress (Leung, 2001b). Furthermore, acculturation as measured by English proficiency differentiated subgroups of Chinese Canadian adolescents (Kuo \& 
Roysircar, 2004; Ying, 2001) and of Asian international students (Sodowsky \& Plake, 1991).

In addition, a concomitant effect of acculturation process is acculturative stress; it is defined as negative behavioral and emotional response attributable to the experiences of adjustment to a new cultural environment (Berry, Kim, Minde, \& Mok, 1987). Among Asian immigrants, Sodowsky and Lai (1997) noted that acculturative stress associated with psychosomatic ailments, anxiety, depression, psychosocial dysfunction, cultural marginality, poor self-concept, eating disorders, and career-choice indecision were prevalent. Acculturative stress may be particularly intense among international students (Leong \& Chou, 2002). Zheng and Berry (1991) found that Chinese sojourners in Canada reported more problems related to work, family and children, language and communication, homesickness, and loneliness than Canadian-born Chinese and non-Chinese samples. The study estimated that as much as $70 \%$ of the sojourners in the study were considered "non-adapted". Compared to their immigrant counterparts, Chung (1994) revealed that unaccompanied sojourners in the US reported more depression, paranoid ideation, and anxiety symptoms. As compared to their American-born counterparts, the same group reported more anxiety in the areas of worry/oversensitivity and social concerns/concentration, somatization, and anxiety symptoms.

Ethnic identity, on the other hand, refers to a movement toward one's ethnic heritage (Roysircar-Sodowsky \& Maestas, 2000). Ethnic identity represents a component of self-concept that is derived from an individual's knowledge of his or her membership in a social group or groups. The individual draws certain value and emotional significance from this membership (Phinney, 1992). There have been mixed observations concerning the relative importance of ethnic identity among foreign-born Asian youth. Roysircar-Sodowsky and Maestas (2000) concluded from their review of the literature that first-generation Asian immigrants were less concerned about their ethnic identity than their US-born counterparts because of the latter group's strong tie to their culture of origin and ethnic group. However, others noted that among foreign-born Chinese immigrants, identification with Chinese heritage is particularly salient. Lay and Verkuyten (1999) found foreign-born Chinese Canadian university students to be more likely to use ethnicity as a selfdescriptor and to see themselves as 'Chinese' more than the Canadian-born students. Among the foreign-born, personal self-esteem was linked to more positive evaluations of their ethnic group (private-collective self-esteem) and with a greater sense of being good members of their ethnic group (member-collective self-esteem). In Ying's (2001) study, Chinese unaccompanied minors in California reported a strong adherence to Chinese cultural identity than their accompanied minor and unaccompanied adult counterparts, despite the fact that all three groups demonstrating a similar level of identification with American cultures. According to Ying, the adherence to cultural identity provides "psychological fueling" for these unaccompanied minors' in their adjustment process and individuation away from their family and country of origin.

In addition, evidence suggests that the interpersonal domains of acculturation, both as related to one's own ethnic community and to members of the host society, 
bear critical importance in the adjustment experience of individuals undergoing cultural changes (Sam \& Berry, 1995; Sodowsky \& Lai, 1997). Interpersonal competence encompasses the extent to which ethnic minority individuals engage in social affiliation with both co-ethnic members and members of the dominant group (Lay \& Nguyen, 1998; Sodowsky \& Lai, 1997). Ward (2001) coined the term "sociocultural adaptation" to describe individuals' ability to execute effective interactions with host nationals. Ward and her colleagues have consistently found sociocultural adaptation to be positively related to psychological adjustment across various groups of migrants. In addition, Sam and Berry (1995) found that the interpersonal variables (i.e., close contact with parents, perceived parental attitudes, number of friends, close contact with adults in the neighborhood, and fluency in Norwegian language) were among the strongest predictors of acculturative stress for immigrant adolescents in Norway.

Competence in the social sphere has been found to predict positive adjustment outcomes for Taiwanese international students in the US as well (Ying, 2002). Leung (2001a) further revealed that among Chinese immigrant adolescents in Australia and Canada, those who had positive social resources and social interaction in the host society were protected from acculturative strains. In a longitudinal study of postsecondary Taiwanese international students in the US, a positive attitude either toward having friendships with Americans or with Taiwanese was a predictor for engaging in cross-cultural interaction (Ying, 2002). Conversely, international students often identified social isolation in the host society as a source of adjustment difficulty. In two recent studies, Leung (2001a, b) found that Chinese immigrants and international students in Canada and Australia reported feeling greater loneliness and less satisfaction with their social life than their non-immigrant counterparts.

Moreover, alienation resulting from being prejudiced and discriminated against by the members of the host society can have a deleterious effect on the quality of international students' or immigrants' adjustment in the host society (Lay \& Nguyen, 1998; Ward, 2001). It is partly due to the fact that perceived prejudice is often a major source of stress for acculturating individuals (Berry, 1997). As noted by some, the combination of being an Asian and being an international student often amplifies the negative experience and perception of prejudice. For instance, in the US (Hwang \& Watanabe, 1990; Kuo, 1991) and Canada (Chow, 1990), Chinese unaccompanied adolescent students identified racial discrimination as a major adjustment stressor during their sojourn. This experience was found to be most prevalent among Asian, foreign-born immigrants and international students (Sodowsky \& Plake, 1992; Ying, Lee, \& Tsai, 2000). It was also positively related to mental health problems among Chinese Canadian immigrants (Dion, Dion, \& Pak, 1992).

\subsection{Research hypotheses: directionality of the relationships among the adaptation variables}

In the present study, we test competing models that predict acculturative stress and ethnic identity among Taiwanese unaccompanied sojourners. The intervariable 
relationships are hypothesized as the following. With respect to the first criterion variable acculturative stress, we stipulate that perceived prejudice, education-related acculturation, interpersonal competence, age of arrival in Canada, and length of stay in Canada will have direct and/or indirect relationships with the degree of stress experienced by Taiwanese unaccompanied sojourners. The participants' report of perceived prejudice will predict more acculturative stress. This relationship is posited as such because Lay and Nguyen (1998) found that acculturating Vietnamese Canadian adolescents' depressive symptoms, an associated manifestation of acculturative stress, to be related to outgroup hassles (i.e., discrimination practiced by the dominant and other ethnic groups). Moreover, in a recent study by Kuo and Roysircar (2004), Chinese Canadian adolescents' degrees of acculturation were found to negatively correlate to their experiences of acculturative stress. This leads to the expectation that education-related acculturation will negatively predict acculturative stress in the hypothesized models. We also hypothesize that interpersonal competence will negatively predict acculturative stress (Leung, 2001a; Ying, 2002). Interpersonal competence will mediate the effects of perceived prejudice and education-related acculturation on acculturative stress. Finally, inline with Kuo and Roysircar's (2004) findings, in which they found age of arrival and length of stay in the host country to be related to acculturative stress, we expect the former to positively predict and the latter to negatively predict acculturative stress, respectively.

In regards to the second criterion variable, ethnic identity, education-related acculturation, interpersonal competence, age of arrival in Canada, and length of stay in Canada will render either direct or indirect effects on participants' ethnic identification. It has been argued that ethnic identity would be less of a concern to foreign-born, first-generation international group because of their strong ties to their culture of origin and ethnic group (Roysircar-Sodowsky \& Maestas, 2000). Thus, we expect weaker overall correlations between ethnic identity and other predictor variables than in the case of acculturative stress. It is posited that education-related acculturation and ethnic identity will form a negative but weak relationship. The two variables have been suggested to be relatively independent constructs, with acculturation representing one's response to the dominant group and ethnic identity exemplifying one's response to his or her ethnic group (Roysircar-Sodowsky \& Maestas, 2000; Ying et al., 2000). In terms of interpersonal competence, it will positively predict sojourners' ethnic identity (Kuo, 1991; Lay \& Nguyen, 1998); in another words, an adolescent sojourner's interpersonal effectiveness and social resources will contribute to the strength of his or her valuing and identifying with Chinese culture. On the other hand, experiences of prejudice and discrimination are likely to render young sojourners feeling ashamed about being different and holding unto their Chinese identity. Consequently, perceived prejudice will negatively predict ethnic identity. We further anticipate that age of arrival will positively relate to ethnic identity: those began their sojourn at an older age will maintain a stronger Chinese identity than those who arrived in Canada at a younger age. Finally, length of stay will negatively predict ethnic identity. Due to a lack of empirical data related to the last two sets of relationships, their directionality and strength are only speculative. 


\subsection{Hypothesized models}

Four recursive (unidirectional) models (see Appendix B) are hypothesized to account for the relationships among the adaptation variables presented in the previous section. In Models $\mathrm{A}$ and $\mathrm{B}$, perceived prejudice, education-related acculturation, interpersonal competence, and age of arrival in Canada are included in the models as predictors of acculturative stress and ethnic identity. In these two models, interpersonal competence is construed as a mediator between perceived prejudice and acculturative stress. In Model B, an additional path from interpersonal competence to ethnic identity is indicated.

In Models $\mathrm{C}$ and $\mathrm{D}$, we additionally introduce a migration-related variable, length of stay in Canada, into the models, to test its relationship to sojourners' acculturative stress and ethnic identity. Using regression analyses, previous studies produced mixed results concerning length of stay on acculturation-related stress. For instance, while Cheng (1994) found increased length of stay in the host country to have negative effects on the psychological well-being of Chinese immigrant youth, other found no effect on their psychological outcomes (i.e., depression or acculturative stress) (Kuo \& Roysircar, 2004; Noh \& Avison, 1996). Thus, in Model C, length of stay is hypothesized to have a direct negative effect on acculturative stress and a direct positive effect on ethnic identity. In the same model, perceived prejudice represents a mediating variable between interpersonal competence and acculturative stress, and between interpersonal competence and ethnic identity. In addition, interpersonal competence will negatively predict acculturative stress and positively predict ethnic identity. In Model D, perceived prejudice, education-related acculturation, age of first arrival, and length of stay are hypothesized to have direct impacts on sojourners' acculturative stress. Additionally, in this model sojourners' interpersonal competence serves to mediate the negative effects of acculturative stress on their sense of ethnic identify. The relative fit of each model will be evaluated against a composite of goodness-of-fit indices recommended by Hoyle and Panter (1995) and compared across models. Furthermore the models will be assessed according to their conceptual fit with the hypothesized intervariable relationships discussed in the previous section.

\section{Method}

\subsection{Participants and procedures}

Two hundred and forty-seven Taiwanese unaccompanied sojourners in the Greater Toronto area participated in the study. They were students from approximately six private and 10 public secondary schools, and several local Taiwanese/Chinese community organizations. All participants completed an individual informed consent/assent form advising of the voluntary and confidential nature of the study, and their rights as participants. Those who were 16 years old and younger were asked additionally to have a signed parental/guardian informed 
consent. Several approaches were undertaken to reach the target population. First, with the permission of participating schools and community groups frequent by Taiwanese adolescents, the first author administered questionnaires in person, onsite at these locations. Second, the questionnaires were administered and collected by social workers and counselors in the participating schools. Finally, a snowball technique was employed; Taiwanese students with whom the first author's knew through his personal contacts were asked to recruit other potential participants.

The total response rate of the participants was $77 \%$, of which a total of 201 usable questionnaires were used for the final analyses. The sample consisted of 130 males and 71 females. This male predominance among Taiwanese unaccompanied sojourners is also reported elsewhere. Lin (1998) noted that compulsory military service for young males and patriarchal values are reasons why Taiwanese parents send their sons abroad for education. The current sample had a mean age of 17.34 $(\mathrm{SD}=1.71)$. Nearly $80 \%$ of the participants came to Canada at age 16 or younger, with 15.14 years of age $(\mathrm{SD}=1.7)$ as the mean age of arrival in Canada. The average length of stay in Canada was approximately 2 years and 3 months $(M=26.5$ months; $\mathrm{SD}=18.02)$, with $29.5 \%$ indicating less than 1 year of residence in Canada. Ninety percent of the respondents reported not living with either of their parents, clearly indicating their unaccompanied status. In terms of pre-arrival preparation in English, 19\% $(n=37)$ had 1 year or less, 52\% $(n=103)$ had $2-3$ years, and only $29 \%(n=58)$ had 4 years or more preparation in English.

\subsection{Development and analysis of the survey questionnaire for the present study}

Since little research has focused on teenage unaccompanied sojourners from Asia, there were no known psychological measures at the time of the study that were designed and validated with this population. In view of this gap, a bilingual (Chinese and English) survey questionnaire was developed by the first author with the objective to construct measures that would take into consideration of the unique sociodemographic, developmental, and cultural characteristics of Taiwanese unaccompanied sojourners. Furthermore, the formulation of the questionnaire was established on an extensive review of the pertinent literature in order to ensure that the items generated align with the constructs of acculturation, acculturative stress, and ethnic identity. As a result, the original questionnaire consisted of items broadly assessed Taiwanese sojourners' demographics, motivation and preparedness for overseas study, acculturation in the academic and interpersonal domains, adherence to Chinese identification, familial relationships, acculturation difficulties and stressors, psychological distress and well-being, and patterns of dealing with stress.

To ensure the linguistic equivalence (between Chinese and English), reliability, and factorial validity of the questionnaire, a number of procedures were taken. First, two bilingual raters independently rated the linguistic equivalence between the English and Chinese translations of the questionnaire. There was a $92 \%$ interrater agreement regarding the equivalence of the two language forms. Second, a pilot administration of the questionnaire with nine Taiwanese students led to minor syntactical changes in 
the questionnaire. Finally, tests of internal consistency (Cronbach's alphas) and factor analysis were conducted.

For the scope and purpose of the present study, only a subset of the items corresponding to the variables under examination were extracted from the questionnaire and eventually included in the analyses. Previous acculturation and acculturative stress research by Sodowsky and Lai (1997) and Sodowsky, Lai, and Plake (1991) on Asian immigrants and international students in the US provided the conceptual basis to guide the inclusion of items and categorization of the adaptation variables. As a result, 62 items (excluding the demographic items) of which content were consistent with either acculturation in the academic and interpersonal realms or acculturation strains (including psychological distress and experiences of discrimination) or Chinese cultural identification were identified (see Appendix A-Part I). These items were then subjected to an exploratory factor analysis, using principal axis factoring and oblimin rotation (assuming that the factors would be correlated). The result yielded five adaptation-related factors. Items with absolute loadings of .30 or higher on one, and only one conceptual similar factor were retained. The factors were: education-related acculturation (11 items; $\alpha=.81$ ), interpersonal competence (eight items; $\alpha=.73$ ), perceived prejudice (two items; $\alpha=.79$ ), acculturative stress (10 items; $\alpha=.87$ ), and ethnic identity (two items; $\alpha=.68$ ). There were four additional items that tapped into the participants' sense of preparedness and readiness before embarking on their sojourn in Canada. This led to a total of 37 items being used in the analyses of the present study (see Appendix A-Part II).

Base on the results of the item analysis, we then proceeded to test the intercorrelations among the five, identified adaptation variables in mediational models, holding acculturative stress and ethnic identity as the dependent variables. To further explore the unique developmental characteristics of Taiwanese unaccompanied sojourners, age of first arrival and length of stay in the host country, which had been found to be important demographic correlates of acculturation in previous studies (Kuo \& Roysircar, 2004; Sodowsky et al., 1991), were added into the models.

\subsection{Measures}

The following sections describe the five adaptation variables obtained from the factor analysis of the questionnaire items (described in the earlier section) and the contents corresponding to these variables. A five-point Likert format was used in all scales presented below; while lower scores represent weaker endorsement of the items stated and higher scores represent stronger endorsement of the items (see Appendix A-Part II).

\subsubsection{Education-related acculturation}

Education-related acculturation represented a specific aspect of acculturation pertained to participants' familiarity with the Canadian educational system, learning environment, and proficiency in the English language. Items assessed the extent to which the participants were able to adapt to various aspects of their educational 
experience in Canada, including teaching styles, study strategies, its learning environment and educational system, study and academic work, courses selection, and career choices that were new and unfamiliar to them; as well as their mastery of English in terms of comprehending, speaking, reading, and writing English.

\subsubsection{Interpersonal competence}

Interpersonal competence tapped into participants' perceived sense of social support and interpersonal effectiveness. Some items assessed the availability of social resources, including the degree to which participants knew others who cared about them, whom they could turn to for help, and whom they considered to be good friends. Participants were also asked whether they could identity a social group with whom they have a sense of belonging. Other items assessed participants' interpersonal effectiveness, including their experience of social isolation and interpersonal conflicts, stress associated with establishing friendship, and perceived difficulties in making friends in Canada.

\subsubsection{Perceived prejudice}

Two items were used to measure participants' experience and perception of prejudice. One addressed the stress associated with having to deal with racial discrimination on a daily basis. The other assessed perceived difficulty in dealing with racial discrimination in school.

\subsubsection{Acculturative stress}

Acculturative stress was measured in terms of self-reported psychological and emotional difficulties. Items included moods swings, feeling depressed without apparent reason, finding life to be pointless, decreased motivation for work or study, worrying about things that did not matter, feeling lonely in the recent past, frequently wanting to 'just go home' to Taiwan, and homesickness that interfered with work.

\subsubsection{Ethnic identity}

Chinese ethnic identity was measured on the basis of participants' affiliation with and commitment to their cultural and linguistic heritages. The participants rated the degree of importance in maintaining their Chinese heritage and in maintaining proficiency in Chinese (Mandarin or Taiwanese).

\section{Results}

\subsection{Preparedness for overseas study}

Approximately $20 \%$ of the participants did not feel adequately prepared for overseas study and the same proportion indicated not being involved in the family's decision-making process to send them abroad. A significant number of the current sample reported feeling ill-prepared $(51 \%)$, not adequately oriented for studying 
abroad (41\%), lacking information about Canada (74\%), and feeling unclear about the purposes of coming to Canada (34\%). From these responses, it appeared that the unaccompanied sojourners found themselves lacking specific information and/or skills related to: (1) the Canadian school system; (2) new study strategies to succeed in the North American school system; (3) ways in which to develop proficiency in English; and (4) handling acculturative stress (e.g., discrimination). The results indicated a significant gap between unaccompanied sojourners' expectations prior to arriving in Canada and the actual demands experienced after being in Canada.

\subsection{Model fitting}

The current sample size $(N=201$; $\mathrm{df}=4)$ and the relative parsimonious models hypothesized in this study made it appropriate to conduct structural equation modeling (SEM), based on the criterion specified by Chou and Bentler (1995). The four hypothesized models were tested using the SEM procedure via analysis of moment structure (AMOS) (Arbuckle, 1995). The full Information Maximum Likelihood procedure was utilized to derive parameter estimates. All parameters in the study were entered into AMOS analyses simultaneously.

Appendix $\mathrm{C}$ shows the fit indices for all four competing models. As revealed in the table, Model A and B fit with the data considerably better than Model C and D. However, between Model A and B, Model B was rejected because it was a less parsimonious model (with one path more) than Model A. In addition, evidence (Tucker-Lewis index (TLI) $=1.002$ indicating the extreme value) pointed toward Model B as overfitting with the data. As a result, Model A was identified as the most parsimonious and the best-fitting model. Table 1 shows the correlation matrix of the six variables within this model, including their respective correlations, means, and standard deviations. Fig. 1 represents this model and its path coefficients for all parameters. This proposed model had a $\chi^{2}$ of 5.604 , which was non-significant $(\rho>.01)$, suggesting that the model is no different from the observed data. Furthermore, the $\chi^{2} / \mathrm{df}=1.401(\mathrm{df}=4)$, reached a desirable level of less than 3 (Kline, 1998).

Other indices also pointed to this model's fitness. We found the TLI to be .999 , exceeding the cutoff point (.95) for a good fit (Hu \& Bentler, 1999). The comparative fit index (CFI) had a value of one, indicating a very good fit (Hoyle \& Panter, 1995). In addition, the root mean square error of approximation (RMSEA), an absolute-fitindex, reached a value of .045, a value less than .06, the cutoff for good model fit $(\mathrm{Hu}$ $\&$ Bentler, 1999). The composite profile of the model, as verified by the provided indices, suggested that the proposed model adequately explained the actual relationships among the six variables.

\subsection{Relationships among variables}

In the best-fitting model, the three exogenous variables, education-related acculturation, perceived prejudice, and age of arrival explained $41 \%$ of the variance in the endogenous variables, interpersonal competence, acculturative stress, and 
Table 1

Correlation, means, and standard deviations among the variables in path analysis

\begin{tabular}{|c|c|c|c|c|c|c|}
\hline Variables & 1 & 2 & 3 & 4 & 5 & 6 \\
\hline 1. Age of arrival & 1.00 & & & & & \\
\hline 2. Education-related acculturation & -.06 & 1.00 & & & & \\
\hline 3. Perceived prejudice & .07 & -.25 & 1.00 & & & \\
\hline 4. Interpersonal competence & .03 & .26 & .15 & 1.00 & & \\
\hline 5. Acculturative stress & .02 & -.36 & .22 & -.38 & 1.00 & \\
\hline 6. Ethnic identity & .11 & .05 & .06 & .16 & -.11 & 1.00 \\
\hline$M$ & 15.14 & 3.14 & 1.95 & 3.28 & 2.55 & 4.30 \\
\hline SD & 1.69 & .60 & .86 & .48 & .69 & .62 \\
\hline
\end{tabular}

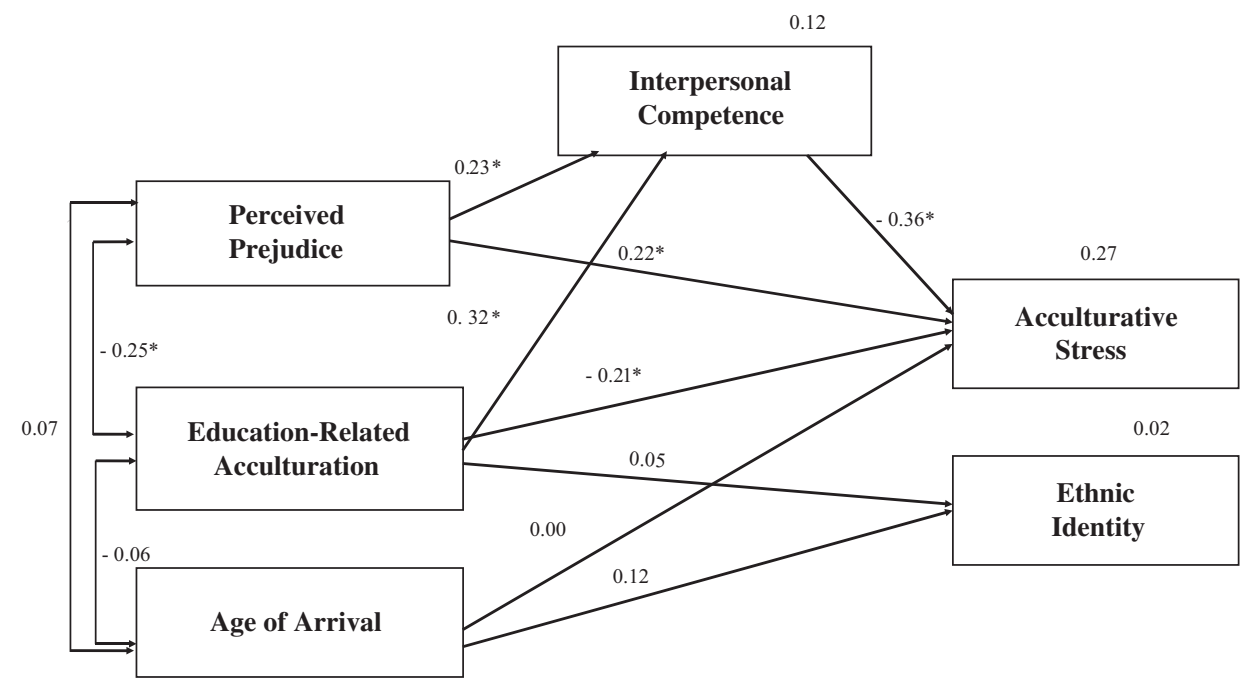

Fig. 1. Path model for acculturative stress and ethnic identity for Taiwanese unaccompanied sojourners. Note: $\chi^{2}(4, N=201)=5.604, \chi^{2} / \mathrm{df}=1.401$, TLI $=.999, \mathrm{CFI}=1, \mathrm{RMSEA}=.045,{ }^{*} \rho<.05$.

ethnic identity (see Fig. 1). This is considered a large effect size, according to Cohen (1988). Inline with our prediction, perceived prejudice formed a significant positive relationship $(\beta=.22 ; \rho<.05)$ with acculturative stress. Evidently, unaccompanied sojourners' sense of being discriminated and excluded by the dominant group significantly led to their experience of stress. Interpersonal competence further mediated this relationship. First, somewhat unexpected, there was a strong positive relationship $(\beta=.23 ; \rho<.05)$ between perceived prejudice and interpersonal competence. Second, there was an unexpected strong negative relationship $(\beta=-.36 ; \rho<.05)$ between interpersonal competence and acculturative stress. 
A significant negative relationship $(\beta=-.21 ; \rho<.05)$ was found between education-related acculturation and acculturative stress which supported our hypothesis. Also, a significant positive relationship $(\beta=.32 ; \rho<.05)$ existed between education-related acculturation and interpersonal competence. Moreover, education-related acculturation formed a significant negative relationship with perceived prejudice $(\beta=-.25 ; \rho<.05)$.

With respect to ethnic identity, it appeared to be unrelated to either educationrelated acculturation or age of arrival in Canada; both paths were non-significant. Furthermore, while a number of studies found relationship between age of arrival and acculturative stress (i.e., Kuo \& Roysircar, 2004; Sodowsky \& Lai, 1997), the current study did not find such a relationship.

\section{Discussion}

The purpose of the study is to explore the characteristics, the preparedness for overseas study, and the cross-cultural adaptation of Taiwanese unaccompanied sojourners. The current exploratory study points out a number of critical adaptation factors that affect these young sojourners' adjustment. First, the extent to which sojourners are able to acclimate themselves to the new academic and linguistic environment in the host country and to become proficient in such a system is an important indicator of their psychological adjustment. The results showed that a higher level of risk for acculturative stress could be anticipated among sojourners who showed low education-related acculturation. In addition, lower acculturation is correlated with more perceived prejudice. These results find support in previous research. Leung (2001b) showed that academic competency in the host society is a critical predictor of positive psychological adaptation among Chinese adolescents in Canada and Australia. Conversely, difficulties in adjusting to new situations were associated with poor academic acculturation. Also, challenges in the academic arena including difficulties in language (English) uptake have been consistently identified as major sources of adjustment strains for unaccompanied students (Chow, 1990; Kuo, 1991). In fact, Kuo and Roysircar's (2004) study showed that in Canada Chinese adolescents' English reading ability positively predicted acculturation and negatively predicted acculturative stress. Thus, acculturation in the academic realm may provide a crucial gauge of a young sojourner's overall adjustment and adaptation. When assessing adolescent sojourners' quality of adjustment in the new cultural environment, particular attention should be directed at evaluating adolescent international students' academic competency.

Second, our path model in the current study revealed a positive relationship between prejudice unaccompanied sojourners perceived and their acculturative stress, supporting previous findings (Kuo, 1991; Ying et al., 2000). Immigrants' and international students' perceptions of prejudice in a White dominant society often exacerbates the stress related to living in two cultural contexts (the ethnic and the White society) and to cross-cultural social interactions (see review in Kuo-Jackson \& Sodowsky, 1999). In another words, the nature of the sojourners' relationship with 
members of the host culture is vital to their psychological well-being. Young unaccompanied sojourners' loneliness and homesickness may be compounded by a sense of social exclusion resulting from discrimination (Hwang \& Watanabe, 1990). As a result, when working and helping these teenage students, issues related to perceived and/or experienced discrimination should be explored at an opportune time. At the personal level, counselors and school personnel should be proactive in processing these issues gently but honestly with international students. Many young foreign students might be extremely hesitant to confront prejudice because of their status as 'guests' in the host country. At the institutional level, organized efforts are needed in preparing unaccompanied sojourners to deal with problems that might arise from race and intergroup relations in North America. These programs should target at preparing students to manage and cope with discrimination by equipping them with necessary information and skills early in their sojourn.

Third, our results underscore the critical role of interpersonal competence as a key mediator of acculturative stress for unaccompanied sojourners. As demonstrated, satisfying social relationship and friendship, and adequate access to social support work to lessen the negative impact of sojourners' acculturative strains resulting from perceived prejudice. Being without parental guidance and protection makes adolescents students particularly vulnerable to isolation and loneliness in host cultures (Lin, 1992). However, sojourners can ensure a greater psychological health and resistance to acculturation strains by cultivating sound social competency and interpersonal resources.

Effective interpersonal competency for international students appears to encompass a "bicultural" competency in two directions. Ying and Liese (1994) found that Chinese international students' affiliation with American friends enhances the students' "functional adjustment", which helps to enhance students' understanding of the dominant society. On the other hand, a strong social tie with co-ethnic members promotes students" "emotional well-being", and offers psychological and emotional support for coping with acculturation strains.

On the basis of these results, we forward the following recommendations for counseling and training adolescent sojourners to achieve positive adaptation in North America. First, we concur with Ying and her colleagues' suggestions to introduce systematic pre- and post-arrival training for young adolescent sojourners. For instance, Ying (2002) advocated for early intercultural intervention programs for post-secondary international students from Taiwan studying in the US. She recommended training programs that are implemented at pre-arrival and/or early phase of sojourn. The content of which would include promoting knowledge of the host country and its educational system, social interaction with individuals from the host culture, communication skills, and ways to cope with prejudice. Our findings indicated that similar efforts are critically needed for adolescent sojourners at the high school level.

Beyond didactic training and information giving, we recommend counselors and educators to give special consideration to unaccompanied sojourners' unique developmental characteristics and acculturation experiences. In the absence of parents or guardians, these young adolescents require even greater emotional 
support and close supervision from other significant adults than adult international students. In addition, an integral part of support for unaccompanied sojourners requires education of and cooperation from the sending parents. Parents need to be educated about the nature of their children's acculturative stress and daily strains being lone sojourners, their children's developmental and emotional needs, and the ways in which they can provide necessary and timely support for their sojourning sons or daughters.

Finally, in terms of research, the present study offers preliminary insights into the adaptation experience of young Taiwanese sojourners in cultural transitions. In particular, the results suggest possible pathways through which key adaptation variables interact to affect the sojourners' psychological well-being and ethnic identification. Moreover, the present study was among the first to construct measures that took into account of the unique sociodemographic characteristics and adaptation experiences of unaccompanied sojourners from Asia. These measures and the measurement model in the present study clearly need further testing and validation. At this stage they offer the initial basis upon which other studies of similar focus and population might built.

\section{Limitations of the current study}

The results of the current study must be carefully interpreted in view of the following limitations. First, the measures used in the present study need to be considered cautiously because the identification of these scales relied heavily on post hoc item analyses. As such, the construct validity of these scales cannot be fully assured in the present exploratory study. Consequently, the measurement model examined in the study should be viewed as tentative. We recommend future study to engage in more rigorous validation procedures to substantiate the validity (i.e., construct, criterion-related, concurrent, and discriminant validities) of the scales and to refine the scales' psychometric properties. Likewise, replications of the present study are imperative to assess the validity and stability of the path model identified in the study. Additionally, future adaptation research of young sojourners would be strengthened with the incorporation of existing, empirically validated measures. Second, the present model did not test other adaptation variables that might be relevant to the cross-cultural adjustment of young sojourners, such as individuals' intercultural competence, coping strategies, relationships with co-ethnic community, etc. (Berry, 1997; Ward, 2001). Future investigations should broaden the scope of the current model by exploring these other adaptation variables and their effects on the adjustment experiences of young sojourners. Finally, the fact that the current sample was recruited exclusively from the Greater Toronto area, the generalizability of the present findings to Asian sojourners elsewhere could only be speculative at this point. There is a need to expand investigations on acculturation of unaccompanied adolescent sojourners by extending to sojourners from broader national (Korea, the People's Republic of China, Hong Kong, etc.) and ethnic backgrounds. 


\section{Conclusion}

The current study provides a preliminary gauge of the characteristics, psychosocial well-being, and adaptation of Taiwanese unaccompanied sojourners in Canada. Our findings showed that these unaccompanied students were a potentially vulnerable segment of international student population. They were found to be ill-prepared for overseas study and adaptation in the new culture. The unaccompanied sojourners' unique demographics, adjustment challenges, and acculturative stress deserve special attention from counselors, social workers, psychologists, teachers, school administrators, and parents alike. In addition, there is a need for current research on international students to expand its scope to incorporate culturally sensitive and empirically sound measures to assess critical adaptation variables, to include other crucial adaptation variables into the conceptualization, and to investigate younger teenage students of diverse national backgrounds.

\section{Acknowledgement}

The authors want to express their appreciation to Graig Enders for assisting the data analyses of this study. 


\title{
Appendix A
}

\section{Part-I: QUESTIONNAIRE}

Please read and consider each of the following questions carefully. Your candid responses are essential to ensure the reliability of the present study. Write in short answers or place a " $/$ " mark in front of the appropriate choice. Please make sure that you answer all the questions.

1. Country of Origin:

2. Gender: Male Female

3. Your Age:

4. How old were you when you first came to Canada?

5. How long have you been in Canada? Year(s) $\operatorname{Month}(\mathrm{s})$

6. Immigrant Status:

\begin{tabular}{lll} 
Original Entry & Present Status & \\
$\square$ & - & Canadian Citizen \\
& Landed Immigrant \\
\hline & & Student Visa \\
& - & Visitor's Visa
\end{tabular}

7. Are you presently living with both of your parents? Yes No

Please think back to the time before coming abroad and assess the following statements below regarding your motivation and preparation for studying in Canada. Circle the appropriate number.

\author{
$1=$ Strongly Disagree \\ 2 = Disagree \\ 3 = Unsure \\ $4=$ Agree \\ 5 = Strongly Agree
}

a. I fully participated in the decision process of coming to Canada.

b. I was given appropriate orientation and preparation before I came to Canada.

c. I felt that I was very well-prepared before coming abroad.

d. I had good idea of what it would be like living and studying in Canada before I came.

e. I had a very clear idea about the purpose(s) of coming to Canada even before I arrived.

Rate the degree of stress of the following events in your daily encounter based on the scale below. Circle the appropriate number.

$1=$ Not at All Stressful

2 = Slightly Stressful

$3=$ Somewhat Stressful

$4=$ Very Stressful

5 = Extremely Stressful
a. Study and academic work
b. Mastering English
c. Choosing of courses
d. Choosing of career
e. Cooking and housework

$\begin{array}{lllll}1 & 2 & 3 & 4 & 5\end{array}$

$\begin{array}{lllllll}1 & 2 & 3 & 4 & 5\end{array}$

$\begin{array}{llllll}1 & 2 & 3 & 4 & 5\end{array}$

123345

12345 
f. Managing one's finance and handling money

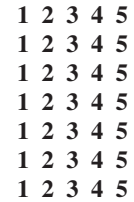

g. Finding accommodation and moving

h. Dealing with immigration

i. Dealing with racial discrimination

j. $\quad$ Making friends

k. Relationship problems

1. Dealing with parents

Please rate the degree of difficulty you face the following aspects of school system in Canada. Circle the appropriate number.

$1=$ Not at All Difficult

2 = Slightly Difficult

3 = Somewhat Difficult

4 = Very Difficult

5 = Extremely Difficult

a. Adapting to the new teaching styles

$\begin{array}{lllll}1 & 2 & 3 & 4 & 5\end{array}$

b. Adapting an effective study strategy

$\begin{array}{lllll}1 & 2 & 3 & 4 & 5\end{array}$

c. Getting accustomed to the different learning environment and educational system

$\begin{array}{lllll}1 & 2 & 3 & 4 & 5\end{array}$

d. Getting involved in extracurricular activities

1223445

e. Getting along with teachers

$\begin{array}{lllll}1 & 2 & 3 & 4 & 5\end{array}$

f. Dealing with peer relationships

$\begin{array}{llllll}1 & 2 & 3 & 4 & 5\end{array}$

g. Dealing with racial discrimination in schoo

$\begin{array}{lllll}1 & 2 & 3 & 4 & 5\end{array}$

h. Comprehending oral English

i. Speaking in English

$\begin{array}{lllll}1 & 2 & 3 & 4 & 5\end{array}$

j. Reading in English

k. Writing in English

Please indicate your view towards your cultural identity.

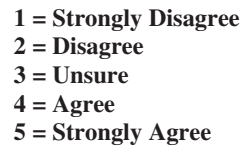

a. It is important for me to maintain Chinese heritage.

b. It is important for me to keep up with the proficiency in Chinese (Mandarin or Taiwanese).

c. It is a disadvantage to be a member of a racial minority.

d. I prefer to be with Chinese-speaking friends than English-speaking friends.

Please respond to the following statements relating to your social and friendship patterns.

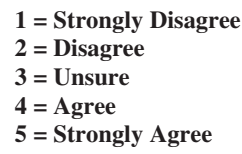

a. I find it hard to make friends in Canada.

b. I am able to find genuinely close/good friends in Canada.

c. I have Canadian friends whom I consider to be my close friends.

d. I participate in activities with Canadians (e.g., school clubs, sports teams or social parties with Canadian friends)

e. I wish that I knew more Canadians.

Please respond to the following statements relating to your emotional and psychological well-being. 
$1=$ Never $\quad 2$ = Rarely $\quad 3$ = Sometimes $\quad 4$ = Often $\quad 5=$ Always

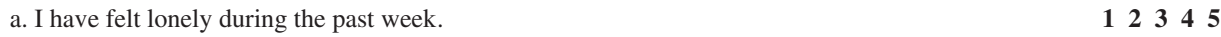

b. I have a group of friends to which I belong. $\quad 122345$

c. I often feel isolated from others. $\quad \begin{array}{rrrrr}\mathbf{2} & \mathbf{3} 4 \mathbf{5}\end{array}$

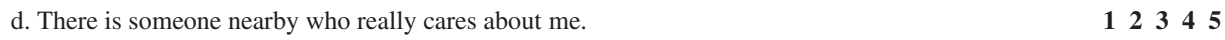

e. I almost always have someone to turn to if I need to talk. $\quad \begin{array}{lllll}\mathbf{2} & \mathbf{3} & \mathbf{5}\end{array}$

f. I frequently have the thoughts of wanting to leave Canada and just go back to Taiwan. $\begin{array}{rrrr}\mathbf{1} & \mathbf{2} & \mathbf{3} & \mathbf{5}\end{array}$

g. I feel very sad whenever thinking about family, parents, relatives and friends back home. $\quad \begin{array}{rrrrr}1 & \mathbf{2} 34 & \mathbf{5}\end{array}$

h. I have felt so homesick to the extent that I could not concentrate on my work at hand. $\quad \begin{array}{lll}\mathbf{2} & \mathbf{4} 5\end{array}$

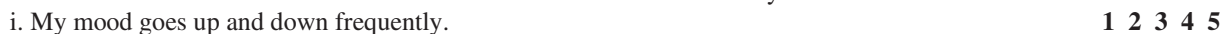

j. I often feel depressed and down without any apparent reason. $\quad \begin{array}{lllll}\mathbf{2} & \mathbf{3} & \mathbf{4} & \mathbf{5}\end{array}$

k. Life often seems so pointless to me. $\quad \begin{array}{rlll}\mathbf{2} & \mathbf{3} 4 \mathbf{5}\end{array}$

1. I often find hard to motivate myself to do work or to study. $\quad \begin{array}{lllll}\mathbf{2} & \mathbf{3} 4 \mathbf{5}\end{array}$

m. I seem to worry unreasonably over things that don't matter much. $\quad \begin{array}{lllll}\mathbf{2} & \mathbf{3} & \mathbf{4} & \mathbf{5}\end{array}$

n. I am often nervous and tense. $\quad \begin{array}{lllll}\mathbf{2} & \mathbf{3} & \mathbf{4} & \mathbf{5}\end{array}$

o. I often feel overwhelmed by all the responsibilities that are on me. $\quad \begin{array}{lllll}\mathbf{2} & \mathbf{3} & \mathbf{5}\end{array}$

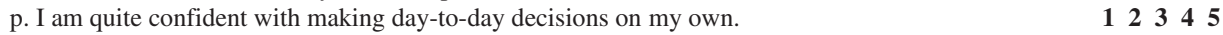

q. I am satisfied with the way I have managed life on my own. $\quad 122345$

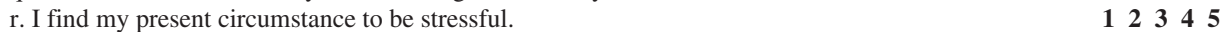

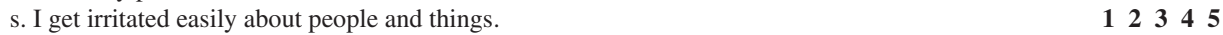

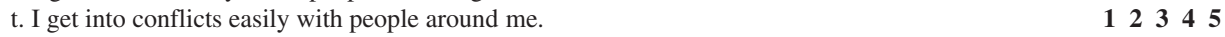

u. I believe that I am capable of doing things as well as most other people. $\quad \begin{array}{llll}\mathbf{2} & \mathbf{3} 4 \mathbf{5}\end{array}$

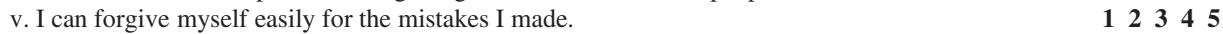

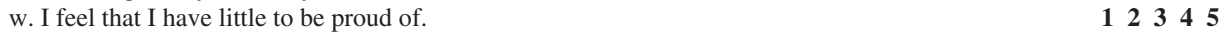

x. I need people to tell me that I am O.K. and what I do is O.K. $\quad \begin{array}{llll}\mathbf{2} & \mathbf{3} 4 \mathbf{5}\end{array}$

y. When people say nice things about me it is difficulty for me to believe them. $\quad 102345$

Part II: Summary of the adaptation variables and their corresponding items in the path models (item retained from the principal axis factor analysis)

\section{Education-related acculturation items:}

1. Rate the degree of difficulty you face with comprehending oral English.

2. Rate the degree of difficulty you face with speaking in English.

3. Rate the degree of difficulty you face with reading in English.

4. Rate the degree of difficulty you face with writing in English.

5. Rate the degree of difficulty you face with adapting to the new teaching style.

6. Rate the degree of difficulty you face with adapting an effective study strategy.

7. Rate the degree of difficulty you face with getting accustomed to the different learning environment and educational system.

8. Rate the degree of stress related to mastering English.

9. Rate the degree of stress related to study and academic work.

10. Rate the degree of stress related to choosing courses.

11. Rate the degree of stress related to choosing career.

\section{Ethnic identity items:}

1. It is important for me to maintain Chinese heritage.

2. It is important for me to keep up with the proficiency in Chinese (Mandarin or Taiwanese).

\section{Interpersonal competence items:}

1. There is someone nearby who really cares about me.

2. I almost always have someone to turn to if I need to talk. 
3. I often feel isolated from others.

4. I have a group of friends to which I belong.

5. I get into conflicts easily with people around me.

6. I find it hard to make friends in Canada.

7. I am able to find genuinely close/good friends in Canada.

8. Rate the degree of stress related to making friends in your daily encounter.

Perceived prejudice items:

1. Rate the degree of stress related to dealing with racial discrimination in your daily encounter.

2. Rate the degree of difficulty you face in dealing with racial discrimination in school.

\section{Acculturative stress items:}

1. My mood goes up and down frequently.

2. I often feel depressed and down without any apparent reason.

3. Life often seems so pointless to me.

4. I often find hard to motivate myself to do work or to study.

5. I seem to worry unreasonably over things that don't matter much.

6. I am often nervous and tense.

7. I often feel overwhelmed by all the responsibilities that are on me.

8. I have felt lonely during the past week.

9. I frequently have the thoughts of wanting to leave Canada and just go back to Taiwan.

10. I have felt so homesick to the extent that I could not concentrate on my work at hand.

Preparedness for overseas study items:

1. I felt that I was very well-prepared before coming abroad.

2. I was given appropriate orientation and preparation before I came to Canada.

3. I had good idea of what it would be like living and studying in Canada before I came.

4. I had a very clear idea about the purpose(s) of coming to Canada even before I arrived. 


\section{Appendix B}

All four Hypothesized models

Model A

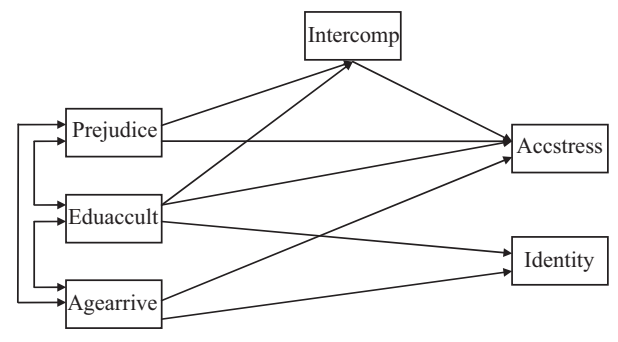

Model C

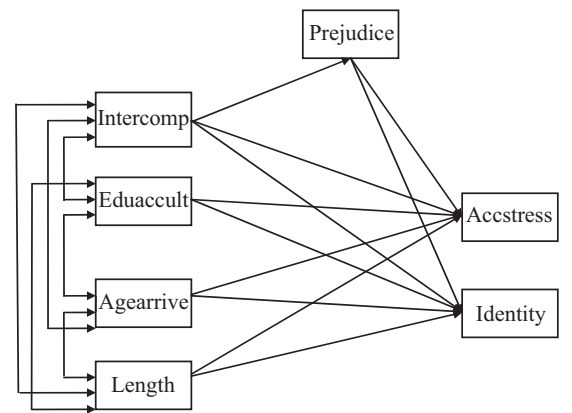

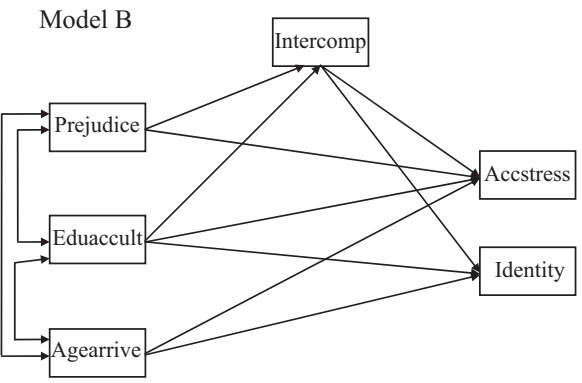

Model D

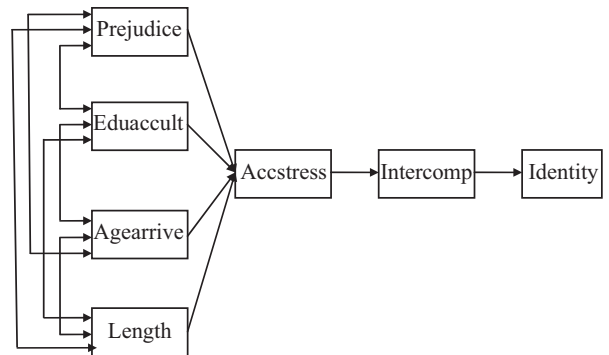

Note: Accstress, acculturative stress; Agearrive, age of arrival in Canada; Eduaccult, education-related acculturation; Identity, ethnic identity; Intercomp, interpersonal competence; Length, length of stay in Canada; Prejudice, perceived prejudice.

Appendix C. Comparative goodness-of-fit indices for the four hypothesized models

\begin{tabular}{|c|c|c|c|c|c|c|c|c|}
\hline & $N$ & $\mathrm{df}$ & $\chi^{2}$ & $p$ & TLI & CFI & RMSEA & Overall fit \\
\hline $\begin{array}{l}\text { Criteria for } \\
\text { significant fit }\end{array}$ & $\mathrm{N} / \mathrm{A}$ & $\mathrm{N} / \mathrm{A}$ & $\mathrm{N} / \mathrm{A}$ & $p>.05$ & $>.90$ & $>.90$ & $<.05$ & $\mathrm{~N} / \mathrm{A}$ \\
\hline Model A & 201 & 4 & 5.604 & .231 & .999 & 1.000 & .045 & Acceptable \\
\hline Model B & 201 & 3 & 1.507 & .681 & $1.002^{\mathrm{a}}$ & 1.000 & .000 & $\begin{array}{l}\text { Poor } \\
\text { (overfitting) }\end{array}$ \\
\hline Model C & 201 & 4 & 22.137 & .000 & .978 & .996 & .151 & Poor \\
\hline Model D & 201 & 9 & 32.941 & .000 & .987 & .994 & .115 & Poor \\
\hline
\end{tabular}


Note: (1) TLI, Tucker-Lewis index; CFI, comparative fit index; RMSEA, root-mean-square error of approximation.

(2) Goodness-of-fit (GFI) index is not reported because it is undefined due to missing data.

(3) The criteria for significant fit indices are defined in accordance with Schumacker and Lomax's (1996, p.

121) summary.

${ }^{a}$ Extreme values suggesting overfitting of the model.

\section{References}

Arbuckle, J. L. (1995). Amos user's guide. Chicago, IL: Smallwaters.

Berry, J. W. (1997). Immigration, acculturation, and adaptation. Applied Psychology: An International Review, 46, 5-34.

Berry, J. W. (2005). Adaptation among ethnocultural groups: An international perspective. Plenary session presented at the meeting of multicultural days: An international perspective, Brock University, St. Catharines, Ont., Canada.

Berry, J. W., Kim, U., Minde, T., \& Mok, D. (1987). Comparative studies of acculturative stress. International Migration Review, 21, 491-511.

Canadian Bureau for International Education. (2002). The national report on international students in Canada 2000/01. Ottawa, Ont.: The Canadian Bureau for International Education.

Chen, E. (1991). Mom and dad a world away: Taiwan high school student in Vancouver. Sinorama, October.

Chen, Y. J. (1997). A study on the parent's decision-making behaviors for the education of the young overseas students. Unpublished master's thesis, National Normal University of Taiwan, Taipei, Taiwan.

Cheng, C. H. (1994). Assessment of depression and risk factors among adolescent Chinese immigrants: A comparative study of accompanied and unaccompanied minors. Unpublished doctoral dissertation, California School of Professional Psychology-Los Angeles, Los Angeles, CA.

Chou, C. P., \& Bentler, P. M. (1995). Estimates and tests in structural equation modeling. In R. H. Hoyle (Ed.), Structural equation modeling: Concepts, issues, and applications (pp. 37-55). Thousand Oaks, CA: Sage.

Chow, H. P. H. (1990). An exodus experience: Difficulties encountered by international high school students. Unpublished master thesis, University of Toronto, Toronto, Ont.

Chung, C. L. E. (1994). An investigation of the psychological well-being of unaccompanied Taiwanese minors/parachute kids. Unpublished doctoral dissertation, University of Southern California, Los Angeles, CA.

Cohen, J. (1988). Statistical power analysis for the behavioral sciences (2nd ed.). Hillsdale, NJ: Lawrence Erlbaum.

Dion, K. L., Dion, K. K., \& Pak, A. W. (1992). Personality-based hardiness as a buffer for discriminationrelated stress in members of Toronto's Chinese community. Canadian Journal of Behavioural Science, 24, 517-536.

Forden, R. W. (1990). Taiwan's "Little overseas students". NAFSA Newsletter, 41, 7-10.

Gordon, M. (1993). Teen-age foreign students left on their own. San Francisco Examiner, B1 \& B2.

Hamilton, D. (1993). A house, cash and no parents. Los Angeles Times, pp. A1, A16

Hong, K. H. (1998). Overseas study by unaccompanied Korean Minors: Current issues and future strategies. In J. C. H. Lin (Ed.), In pursuit of education: Young Asian students in the United States (pp. 27-43). CA: Pacific Asia Press.

Hoyle, R. H., \& Panter, A. T. (1995). Writing about structural equation models. In R. H. Hoyle (Ed.), Structural equation modeling: Concepts, issues, and applications (pp. 76-99). Thousand Oaks, CA: Sage.

Hu, L., \& Bentler, P. M. (1999). Cutoff criteria for fit indexes in covariance structure analysis: Conventional criteria versus new alternatives. Structural Equation Modeling, 6, 1-55.

Hwang, H. T. \& Watanabe, T. H. (1990). Little overseas students from Taiwan: A look at the psychosocial adjustment issues. Unpublished master's thesis, University of California at Los Angeles, Los Angeles, CA. 
Kim, B. S. K., \& Abreu, J. M. (2001). Acculturation measurement: Theory, current instruments, and future directions. In J. G. Ponterotto, J. M. Casas, L. A. Suzuki, \& C. M. Alexander (Eds.), Handbook of multicultural counselling, (2nd ed.) (pp. 394-424). Thousand Oaks, CA: Sage.

Kim, S. C. (1998). Young Korean students in the United States. In J. C. H. Lin (Ed.), In pursuit of education: Young Asian students in the United States (pp. 44-54). CA: Pacific Asia Press.

Kline, R. B. (1998). Principle and practice of structural equation modeling. New York: The Guilford Press.

Knight, J. (2000). Progress and promise: The AUCC report on internationalization at Canadian universities. Ottawa, Ont.: Association of University and Colleges of Canada.

Kuo, B. C. H., \& Roysircar, G. (2004). Predictors of acculturation for Chinese adolescents in Canada: Age of arrival, length of stay, social class, and English reading ability. Journal of Multicultural Development and Counselling, 32, 143-154.

Kuo, S. Y. (1991). You tai wan chieng wang mei guo de shao liu shu sheng wen ti ju ying jou (Research on Taiwanese unaccompanied minors in the United States). Taipei, Taiwan: The Institute of American Culture, Academia Sinica.

Kuo-Jackson, P. Y., \& Sodowsky, G. R. (1999). Cultural ethnic identity versus political ethnic identity: Theory and research on Asian Americans. In D. S. Sandhu (Ed.), Asian and Pacific Islander Americans: Issues and concerns for counselling and psychotherapy. New York, NY: Nova Sciences.

Lay, C., \& Nguyen, T. (1998). The role of acculturation-related and acculturation non-specific daily hassles: Vietnamese-Canadian students and psychological distress. Canadian Journal of Behavioural Science, 30, 172-181.

Lay, C., \& Verkuyten, M. (1999). Ethnic identity and its relation to personal self-esteem: A comparison of Canadian-born and foreign-born Chinese adolescents. Journal of Social Psychology, 139, 288-299.

Lee, P. L. M. (1994). Hong Kong visa students in secondary schools in Metropolitan Toronto. Toronto, Ont.: Joint Center for Asian Pacific Studies.

Leong, F. T. L., \& Chou, E. L. (2002). Counselling international students and sojourners. In P. B. Pedersen, J. G. Draguns, W. J. Lonner, \& J. E. Trimble (Eds.), Counselling across cultures, (5th ed.) (pp. 185-208). Thousand Oaks, CA: Sage.

Leung, C. (2001a). The psychological adaptation of overseas and migrant students in Australia. International Journal of Psychology, 36, 251-259.

Leung, C. (2001b). The sociocultural and psychological adaptation of Chinese migrant adolescents in Australia and Canada. International Journal of Psychology, 36, 8-19.

Lin, J. C. H. (Ed.). (1992). Fan yang de hai tze [Children who go abroad]. Taipei, Taiwan: Teacher Chang Press.

Lin, J. C. H. (1998). Young Taiwanese students in the United States. In J. C. H. Lin (Ed.), In pursuit of education: Young Asian students in the United States (pp. 4-17). CA: Pacific Asia Press.

Noh, S., \& Avison, W. R. (1996). Asian immigrants and the stress process: A study of Koreans in Canada. Journal of Health and Social Behavior, 37, 192-206.

Pedersen, P. (1991). Counselling international students. The Counselling Psychologist, 19, 10-58.

Phinney, J. S. (1992). The multigroup ethnic identity measure: A new scale for use with diverse groups. Journal of Early Adolescence, 7, 156-176.

Roysircar, G. (2004). Counselling and psychotherapy for acculturation and ethnic identity concerns with immigrant and international student clients. In T. B. Smith (Ed.), Practicing multiculturalism: Affirming diversity in counselling and psychology. Boston, MA: Allyn \& Bacon.

Roysircar-Sodowsky, G., \& Maestas, M. (2000). Acculturation, ethnic identity, and acculturative stress: Evidence and measurement. In R. H. Dana (Ed.), Handbook of cross-cultural and multicultural personality assessment (pp. 131-172). Mahwah, NJ: Lawrence Erlbaum.

Sam, D. L., \& Berry, J. W. (1995). Acculturative stress and young immigrants in Norway. Scandinavian Journal of Psychology, 36, 10-24.

Schumacker, R. E., \& Lomax, R. G. (1996). Beginner's guide to structural equation modeling. Mahwah, NJ: Lawrence Erlbaum.

Sieu, M. (1998). Crossing new schoolhouse borders: Young overseas students from Asia. In J. C. H. Lin (Ed.), In pursuit of education: Young Asian students in the United States (pp. 123-134). CA: Pacific Asia Press. 
Sodowsky, G. R., \& Lai, E. W. (1997). Asian immigrant variables and structural models of cross-cultural distress. In A. Booth (Ed.), International migration and family change: The experience of US immigrants (pp. 221-234). Hillsdale, NJ: Lawrence Erlbaum.

Sodowsky, G. R., Lai, E. W., \& Plake, B. S. (1991). Moderating effects of sociocultural variables on acculturation variables of Hispanics and Asian Americans. Journal of Counselling and Development, 70, 194-204.

Sodowsky, G. R., \& Plake, B. S. (1991). Psychometric properties of the American-international relations scale. Educational and Psychological Measurement, 51, 207-216.

Sodowsky, G. R., \& Plake, B. S. (1992). A study of acculturation differences among international people and suggestions for sensitivity to within-group differences. Journal of Counselling and Development, 71, 53-59.

Ward, C. (2001). The A, B, Cs of acculturation. In D. Matsumoto (Ed.), Handbook of culture and psychology (pp. 411-445). New York: Oxford University Press.

Watanabe, T. H. (1989). 'Child-dumping': Taiwan teens left to struggle in US. San Jose Mercury News, pp. A1, A10.

Ying, Y. (2001). Migration and cultural orientation: An empirical test of the psychoanalytical theory in Chinese Americans. Journal of Applied Psychoanalytical Studies, 3, 409-430.

Ying, Y. (2002). Formation of cross-cultural relationships of Taiwanese international students in the United States. Journal of Community Psychology, 30, 45-55.

Ying, Y., Lee, P. A., \& Tsai, J. L. (2000). Cultural orientation and racial discrimination: Predictors of coherence in Chinese American young adults. Journal of Community Psychology, 28, 427-442.

Ying, Y., \& Liese, L. H. (1994). Initial adjustment of Taiwanese students in the United States: The impact of post-arrival variables. Journal of Cross-Cultural Psychology, 25, 466-477.

Zheng, X., \& Berry, J. W. (1991). Psychological adaptation of Chinese sojourners in Canada. International Journal of Psychology, 26, 451-471. 